\title{
Predictors of caregivers' burden of Parkinson's disease in India: experience of a tertiary care center in India
}

\author{
This article was published in the following Dove Press journal: \\ Journal of Parkinsonism \& Restless Legs Syndrome \\ 5 November 2012 \\ Number of times this article has been viewed
}

\author{
Vikas Agrawal' \\ Vinay Goyal ${ }^{2}$ \\ Garima Shukla² \\ Madhuri Behari² \\ 'Department of Neurology, Yashoda \\ Hospital, Secunderabad, Andhra \\ Pradesh, India; ${ }^{2}$ Department of \\ Neurology, All India Institute of \\ Medical Sciences, New Delhi, India
}

Correspondence: Vikas Agrawal Department of Neurology, Yashoda Hospital, Secunderabad, Andhra Pradesh, India, PIN 500003

Tel +9 I 8008290 I I I

Email vikas23bhu@rediffmail.com
Introduction: Parkinson's disease (PD) is a progressive neurodegenerative disorder characterized by increasing dependence on caregivers for activities of daily living that imposes a major burden upon the patients' caregiver. Caregiver burden (CB) refers to the physical, mental, and socioeconomic problems experienced by the caregivers of chronic patients.

Patients and methods: This is a onetime cross-sectional observational study carried out in the movement disorder clinic of a tertiary referral center in India. Persons with PD were interviewed and information was collected regarding demographic and clinical details, treatment taken, and presence of non-motor features such as dementia, psychosis, depression, etc, on a pre-tested format and their caregivers were interviewed for self-perceived burden using Zerit's caregivers' burden inventory.

Results: We interviewed 91 persons with PD (71 [78\%] men, 20 [22\%] women) with their primary caregivers. The age of the patients ranged from 25 to 75 years (mean $56.66 \pm 11.83$ years). After regression analysis, depression in patients (beta $=0.352,95 \%$ confidence interval [CI]: 0.275 to 0.790 ), high UPDRS-motor scores (beta $=0.255,95 \%$ CI: 0.108 to 0.532 ), and presence of sleep disturbances in the atient (beta $=0.206,95 \% \mathrm{CI}$ : 0.817 to 11.823 ) were associated with increased caregiver burden and the presence of multiple caregivers was associated with lower caregiver burden (beta $=-0.311,95 \% \mathrm{CI}:-10.155$ to -3.436 ).

Conclusion: The total number of caregivers was found to be an important predictor for reducing $\mathrm{CB}$. Multiple caregivers is a phenomenon which has not been studied till now. Other factors which were found to have adverse predictive effect on caregiver burden are presence of depression, high UPDRS-motor scores, and sleep disturbances in patients.

Keywords: caregiver, burden, Parkinson's disease, predictors

\section{Introduction}

Parkinson's disease (PD) is a common progressive neurodegenerative disorder characterized by increasing dependence on caregivers for activities of daily living that imposes a major burden upon the patient's caregiver. Caregiver burden $(\mathrm{CB})$ refers to the physical, mental, and socioeconomic problems experienced by the caregivers of chronic disease patients. ${ }^{1}$ Patients of chronic illness with a caregiver have a better outcome in terms of morbidity, mortality, and quality of life. Caregiver stress is an important predictor for early and recurrent hospitalization/institutionalization of patients. Assessment of the burden of caregivers helps to develop comprehensive management strategies both for patients and their caregivers. Caregivers of patients with various diseases frequently report sleep disturbances and depressive symptoms. The care intensity for individuals with PD is mainly influenced by the severity of their motor impairment. The severity of their motor 
impairment is associated with the duration of disease, age of patient, and other comorbidities such as depression, dementia, sleep fragmentation, nocturnal pain, and cramps.

There are very few reports on $\mathrm{CB}$ in caregivers of PD patients, and information regarding relationship between the well-being of caregivers, caregiver stressors, and protective factors are rather scanty. In this study we aimed to find various predictors of CB of caregivers of persons with PD in India.

\section{Patients and methods}

This is a cross-sectional, one time observational study carried out in the movement disorder clinic of a tertiary referral center in India. All consecutive patients of Parkinson's disease (PD) satisfying UK Parkinson's disease brain bank clinical diagnostic criteria ${ }^{2}$ seen in movement disorders clinic or admitted in Neurology wards between January 2009 and January 2010 with a stable caregiver were evaluated along with their caregivers. A stable caregiver was defined as any person who was living with the patient, was primarily and directly involved in patient care and was affected by the patient's status. ${ }^{3}$ Caregivers belonging to a social support network or a professional group were excluded (only two caregivers were excluded). Patients or caregivers, who were not able to complete self-assessment questionnaires, were also excluded. An informed consent was taken from the patients and their caregivers. The study was approved by the Institute Research Review Board and Ethics committee.

Patients with PD were divided into two groups according to the age of onset; age of onset $\leq 40$ years (young onset PD [YOPD]) and $>40$ years (later onset PD). Demographic details, clinical history, and clinical examination were recorded in a pre-tested format. All patients were evaluated by the Unified Parkinson's Disease Rating Scale $(\mathrm{UPDRS})^{4}$, modified Hoehn and Yahr staging (H\&Y), ${ }^{5-7}$ modified Schwab and England Activities of Daily Living Scale (S\&E-ADL), Beck's Depression Inventory (BDI) ${ }^{8}$ Brief Psychiatry Rating Scale (BPRS), ${ }^{9}$ and Mini Mental Status Examination (MMSE). PD patients were asked about the presence of autonomic symptoms, which were graded according to a Likert scale $(0=$ absence of the symptom, $4=$ most severe symptom). The symptoms asked about were postural dizziness/syncope, urinary symptoms, erectile dysfunction, constipation, swallowing problems, sweating disturbance similar to Scales for Outcomes in Parkinson Disease-autonomic (SCOPA-aut). ${ }^{10}$ The score was thus calculated as the autonomic score.

\section{Caregivers}

Stable caregivers as defined above were assessed for their age, sex, relation to patient, occupation, monthly income, monthly expenditure on treatment, total monthly expenditure of the family, number of dependants, number of caregivers taking turns in caregiving, other persons involved in caregiving to the patient, time devoted for caregiving, and other causes (apart from the patient's disease) for stress. All caregivers were assessed using Zarit et al's caregiver burden inventory (ZCBI), ${ }^{11} \mathrm{BDI}$, World Health Organization's quality of life scale (WHO-QOLBREF), ${ }^{12}$ and Short Form 36 (SF36). ${ }^{13}$ Assessment of the patient and caregiver pair took about 90-120 minutes, which was usually carried out in separate interviews.

\section{Statistical analysis}

SPSS software (v 16; SPSS, Inc, Chicago, IL) was used for data analysis. Continuous variables were correlated by Spearman's rank correlation coefficient. The KruskalWallis test was used to correlate H\&Y score with scales used to assess CB and caregivers' quality of life. Patients' categorical variables were correlated with caregivers' continuous parameters using the Mann-Whitney $U$-test. Linear regression analysis was performed to look for the independent predictors of CB. ZCBI was taken as the dependent factor.

\section{Results}

We interviewed 91 PD patient and caregiver pairs. The age of the patients at interview, age of onset of PD, and duration of PD ranged from 25 to 75 years (mean $56.66 \pm 11.83$ ), 18-72 years (mean $49.29 \pm 11.74$ ), and $1-22$ years (mean $7.35 \pm 1.33$ ), respectively (Tables 1 and 2 ). Seventy-one $(78 \%)$ patients were male and $25(27.5 \%)$ patients had young onset PD. The majority $(n=82,90.1 \%)$ of PD patients had tremor-dominant PD while only nine patients had the akinetic rigid type of PD. The mean age of the caregiver was $44.63 \pm 14.27$ years (range $21-70$ ). The caregivers' relationship to the patient included: wife $(\mathrm{n}=38)$, husband $(\mathrm{n}=7)$, sons $(\mathrm{n}=24)$, daughter $(\mathrm{n}=8)$, sibling $(\mathrm{n}=7)$, daughter-in-laws $(n=2)$, grandchildren $(n=5)$. The mean number of dependents (excluding the patient) in the family was $3.82 \pm 1.65$ (range $0-10$ ). Fifty (56\%) caregivers were female. Most of the caregivers were either gainfully employed $(51.6 \%)$ or housewives $(42.9 \%)$. Most of the caregivers of patients were either their spouse $(49.5 \%)$ or children (35.2\%). Nine caregivers reported reasons for stress other than the caregiving (such as unemployment or family 
Table I Descriptive statistics of patients and caregivers (categorical variables)

\begin{tabular}{|c|c|c|}
\hline \multirow[t]{2}{*}{ Variable } & \multicolumn{2}{|l|}{ Number (\%) } \\
\hline & Patient & Caregiver \\
\hline \multicolumn{3}{|l|}{ Sex } \\
\hline Male & $71(78)$ & $4 I(45 . I)$ \\
\hline Female & $20(22)$ & $50(54.9)$ \\
\hline Age mean $\pm S D$ (years) & $56.66 \pm 11.83$ & $44.63 \pm 14.27$ \\
\hline YOPD & $25(27.5)$ & \\
\hline Later onset PD & $66(72.5)$ & \\
\hline \multicolumn{3}{|l|}{ Type of PD } \\
\hline Tremor dominant & $82(90.1)$ & \\
\hline Akinetic rigid dominant & $9(9.9)$ & \\
\hline \multicolumn{3}{|l|}{ Dystonia } \\
\hline Yes & $29(31.9)$ & \\
\hline \multicolumn{3}{|l|}{ Frequent falls } \\
\hline Yes & $28(30.8)$ & \\
\hline \multicolumn{3}{|l|}{ Depression } \\
\hline Yes & $22(24.2)$ & \\
\hline \multicolumn{3}{|l|}{ Thought disorder } \\
\hline Yes & $13(14.3)$ & \\
\hline \multicolumn{3}{|l|}{ Hallucinations } \\
\hline Yes & $14(15.6)$ & \\
\hline \multicolumn{3}{|l|}{ Dyskinesia } \\
\hline Yes & $31(34.1)$ & \\
\hline \multicolumn{3}{|l|}{ Autonomic symptom } \\
\hline Yes & $31(34.1)$ & \\
\hline \multicolumn{3}{|l|}{ Sleep disturbance } \\
\hline Yes & $54(59.3)$ & \\
\hline \multicolumn{3}{|c|}{ Caregiver's relationship to patient } \\
\hline Spouse & & $45(49.5)$ \\
\hline Children & & $32(35.2)$ \\
\hline Siblings & & $7(7.7)$ \\
\hline Others & & $7(7.7)$ \\
\hline \multicolumn{3}{|l|}{ Caregiver employment } \\
\hline Housewife & & $39(42.9)$ \\
\hline Gainfully employed & & $47(51.6)$ \\
\hline Other - retired, student & & $5(5.5)$ \\
\hline \multicolumn{3}{|l|}{ Duration of care/day } \\
\hline$<6$ hours & & $15(16.5)$ \\
\hline $6-12$ hours & & $45(49.5)$ \\
\hline$>12$ hours & & $31(34.1)$ \\
\hline \multicolumn{3}{|c|}{ Other reasons for stress in caregiver } \\
\hline Yes & & $9(9.9)$ \\
\hline No & & $82(91.1)$ \\
\hline
\end{tabular}

stress). The duration of the disease was inversely correlated with the caregivers' WHO-QOL-BREF and SF36 (Spearman's rank correlation coefficient $-0.446[P<0.001]$ and $-0.332[P=0.002]$, respectively), and positively with caregivers' BDI and ZCBI (Spearman's rank correlation coefficient $0.382[P<0.001]$ and $0.503[P<0.001]$, respectively). Autonomic scores, BPRS, and BDI of PD patients also correlated significantly with WHO-QOL-BREF, SF36, ZCBI, and BDI of the caregiver (Table 3).
The caregivers' age did not correlate with caregivers' variables; however, higher monthly income of caregiver was associated with better quality of life, better general physical and mental health status as measured on SF36, and less burden and depression. Monthly expenditure on treatment, total family expenditure, and number of dependants did not correlate with any parameters. However, number of caregivers (many patients had multiple caregivers) was significantly associated with lesser caregivers' burden and better caregivers' quality of life. (Table 3).

The Kruskal-Wallis test showed significant positive correlation between the H\&Y scale and CB. Sleep disturbances in patients and dyskinesia correlated significantly with $\mathrm{CB}$ and quality of life. The presence of dystonia in patients resulted in higher ZCBI and BDI scores in caregivers (Table 4).

Regression analysis was performed with ZCBI as a dependent factor and sleep disturbance, dyskinesia, dystonia, autonomic scores, BPRS, total number of caregivers, UPDRSADL, motor and complications scores, patients' BDI score, $\mathrm{H} \& \mathrm{Y}$ staging, and Schwabb and England scores as independent factors. Regression analysis revealed the presence of depression in patients as the best predictor of $\mathrm{CB}$ (beta $=0.352$, 95\% confidence interval [CI]: 0.275 to 0.790 ) followed by the number of caregivers, suggesting multiple caregivers was associated with lower CB (beta $=-0.311,95 \%$ CI: -10.155 to -3.436 ). Other independent factors which were found to be significant predictors of caregiver burden after regression analysis were UPDRS-motor score and sleep disturbances in the patient (beta $=0.255,95 \%$ CI: 0.108 to 0.532 and beta $=0.206$, 95\% CI: 0.817 to 11.823 , respectively) (Table 5).

\section{Discussion}

The data from the $91 \mathrm{PD}$ patient and caregiver pairs attending the movement disorders clinic or admitted to the Neurology wards in a tertiary care teaching hospital in India showed in a robust manner that $\mathrm{CB}$ is negatively correlated with the number of caregivers, and positively correlated with the severity of PD (as measured by H\&Y stage and UPDRS-motor scale), presence of depression, sleep problems, dyskinesia, and dystonia in patients. Higher numbers of caregivers improved the caregivers' quality of life. All the PD patients included in the study were residing in their house and none were institutionalized.

The total number of caregivers was found to be an important predictor for caregiver stress. It also correlated positively with parameters of quality of life and SF36. However, it correlated negatively with the BDI and ZCBI, 
Table 2 Descriptive statistics of the patients and caregivers (continuous variables)

\begin{tabular}{|c|c|c|c|c|}
\hline & Minimum & Maximum & Mean/median & SD \\
\hline \multicolumn{5}{|l|}{ Patient variables } \\
\hline Patient age & 25 & 75 & 56.66 & 11.83 \\
\hline Age of onset (years) & 18 & 72 & 49.29 & 11.74 \\
\hline Duration of disease (years) & 1 & 22 & 7.35 & 4.04 \\
\hline UPDRS - mental & 0 & 7 & 2.24 & 1.33 \\
\hline UPDRS - ADL & 2 & 33 & 15.77 & 5.86 \\
\hline UPDRS - motor & 5 & 69 & 35.11 & 12.16 \\
\hline UPDRS - complications & 0 & 12 & 3.10 & 3.52 \\
\hline S\&E score & 10 & 100 & 62.75 & 19.26 \\
\hline H\&Y score & I & 5 & 2.95 & 0.83 \\
\hline Autonomic score & 0 & 14 & 3.37 & 3.64 \\
\hline BPRS & 14 & 70 & 33.95 & 11.38 \\
\hline $\mathrm{BDI}$ & 1 & 47 & 14.85 & 9.99 \\
\hline \multicolumn{5}{|l|}{ Caregiver variables } \\
\hline Age & 21 & 70 & 44.63 & 14.269 \\
\hline Number of dependants & 0 & 10 & 3.82 & 1.651 \\
\hline Total number of caregivers & 1 & 4 & 1.69 & 0.694 \\
\hline Monthly income (rupees) & 2500 & 70000 & 12000 & \\
\hline Monthly expenditure on drugs (rupees) & 0 & 8000 & 1312.64 & 1440.6 \\
\hline Total monthly household expenditure (rupees) & 2000 & 40000 & 10000 & \\
\hline WHO-QOL-BREF domain I & 60 & 140 & 97.58 & 16.92 \\
\hline WHO-QOL-BREF domain 2 & 46 & 116 & 84.42 & 15.74 \\
\hline WHO-QOL-BREF domain 3 & 28 & 96 & 51.12 & 13.42 \\
\hline WHO-QOL-BREF domain 4 & 74 & 144 & 104.07 & 17.86 \\
\hline WHO-QOL-BREF total & 154 & 456 & 331.76 & 53.78 \\
\hline SF36 - physical health & 35.4 & 101.0 & 67.974 & 16.18 \\
\hline SF36 - mental health & 34.5 & 104.0 & 70.627 & 17.45 \\
\hline SF36 - score total & 35.50 & 102.00 & 69.95 & 15.9 \\
\hline $\mathrm{ZCBI}$ & 3 & 63 & 34.20 & 15.09 \\
\hline BDI & 2 & 43 & 19.37 & 11.533 \\
\hline
\end{tabular}

Abbreviations: BDI, Beck's Depression Inventory; BPRS, Brief Psychiatry Rating Scale; H\&Y, Hoehn and Yahr staging; S\&E, Schwab and England Activities of Daily Living Scale; SF36, Short Form 36; UPDRS, Unified Parkinson's Disease Rating Scale; WHO-QOL-BREF, World Health Organization quality of life scale; ZCBI, Zerit's Caregiver Burden Inventory.

indicating that fewer caregivers is associated with higher levels of depression and burden in the caregivers. Multiple caregivers is a phenomenon which has not been studied until now and is rather unique in India where people live in joint families with grown-up children and grandchildren. Apart from primary caregivers, there are other family members who take part in caregiving, thus giving respite to the primary caregiver.

Patients' depression was found to be the most important predictor for $\mathrm{CB}$ on regression analysis (beta $=0.352,95 \%$ CI: 0.275 to 0.790 ). It also correlated with the caregivers' depression and inversely correlated with caregivers' quality of life and SF36 scores. Our study clearly shows that if a patient is depressed, it increases CB significantly. Depression in PD patients adversely affects the caregivers' quality of life and general physical health also. Early diagnosis and treatment of depression in patients may therefore relieve some burden of caregivers and improve their quality of life. Many other studies have found depression as the most important predictor for CB using different scales. ${ }^{14-16}$ Another study also found it was a significant factor for CB. ${ }^{17}$

Many studies have shown association between severity of disease and CB in PD. All four subscores of UPDRS were found to be significantly associated with $\mathrm{CB}^{17,18}$; however, UPDRS motor scores were found to have the most robust association with $\mathrm{CB}$. The UPDRS score that measures various symptoms, motor signs, and complications of advanced $\mathrm{PD}$ in a holistic manner was also found to affect $\mathrm{CB}$. UPDRS also correlated significantly with the caregivers' quality of life and SF36. CB, quality of life, and depression correlated significantly with higher H\&Y stage. As the disease progressed, CB and depression increased, and their quality of life deteriorated.

Sleep problems in the PD patients was also found to be a significant factor affecting CB. The effect of patients' sleep on $\mathrm{CB}$ has not been studied in detail in the past; one study showed sleep disturbances in patients also affected the caregivers' sleep adversely. ${ }^{21}$ We studied several aspects of sleep 
Table 3 Spearman's rank correlation coefficient (CC)

\begin{tabular}{|c|c|c|c|c|c|c|}
\hline & WHO-QOL & BDI & ZCBI & $\begin{array}{l}\text { SF36 - physical } \\
\text { health }\end{array}$ & $\begin{array}{l}\text { SF36 - mental } \\
\text { health }\end{array}$ & SF36 - total \\
\hline \multicolumn{7}{|c|}{ Patient variables } \\
\hline \multicolumn{7}{|c|}{ Duration of disease } \\
\hline $\mathrm{CC}$ & $-0.446 * *$ & $0.382 * *$ & $0.503^{* *}$ & $-0.312 * *$ & $-0.252 *$ & $-0.322 * *$ \\
\hline Significance & 0.000 & 0.000 & 0.000 & 0.003 & 0.016 & 0.002 \\
\hline \multicolumn{7}{|c|}{ Autonomic score } \\
\hline $\mathrm{CC}$ & $-0.460 * *$ & $0.424 * *$ & $0.469 * *$ & $-0.324 * *$ & $-0.252 *$ & $-0.359 * *$ \\
\hline Significance & 0.000 & 0.000 & 0.000 & 0.002 & 0.016 & 0.001 \\
\hline \multicolumn{7}{|l|}{ BPRS } \\
\hline $\mathrm{CC}$ & $-0.557 * *$ & $0.331 * *$ & $0.402^{* *}$ & $-0.420 * *$ & $-0.386 * *$ & $-0.456 * *$ \\
\hline Significance & 0.000 & 0.001 & 0.000 & 0.000 & 0.000 & 0.000 \\
\hline \multicolumn{7}{|l|}{$\mathrm{BDI}$} \\
\hline $\mathrm{CC}$ & $-0.503 * *$ & $0.490 * *$ & $0.479 * *$ & $-0.266^{*}$ & -0.180 & $-0.268^{*}$ \\
\hline Significance & 0.000 & 0.000 & 0.000 & 0.011 & 0.087 & 0.010 \\
\hline \multicolumn{7}{|c|}{ Caregiver variables } \\
\hline \multicolumn{7}{|c|}{ Caregiver's age } \\
\hline $\mathrm{CC}$ & 0.146 & $-0.22 I^{*}$ & $-0.219 *$ & $0.172^{* *}$ & 0.215 & 0.160 \\
\hline Significance & 0.21 & 0.035 & 0.037 & 0.069 & 0.061 & 0.053 \\
\hline \multicolumn{7}{|l|}{ Monthly income } \\
\hline $\mathrm{CC}$ & $0.244^{*}$ & $-0.399 * *$ & $-0.382 * *$ & 0.376 & 0.143 & $0.227 *$ \\
\hline Significance & 0.020 & 0.000 & 0.000 & 0.04 & 0.177 & 0.031 \\
\hline \multicolumn{7}{|c|}{ Number of dependants } \\
\hline $\mathrm{CC}$ & 0.102 & 0.002 & 0.142 & 0.015 & -0.057 & 0.067 \\
\hline Significance & 0.337 & 0.985 & 0.180 & 0.885 & 0.591 & 0.527 \\
\hline \multicolumn{7}{|c|}{ Monthly expenditure on drugs } \\
\hline $\mathrm{CC}$ & 0.120 & -0.078 & 0.011 & 0.051 & $0.212^{*}$ & 0.065 \\
\hline Significance & 0.257 & 0.460 & 0.919 & 0.629 & 0.044 & 0.542 \\
\hline \multicolumn{7}{|c|}{ Total monthly expenditure } \\
\hline $\mathrm{CC}$ & 0.140 & -0.196 & $-0.233^{*}$ & 0.031 & 0.126 & 0.181 \\
\hline Significance & 0.186 & 0.063 & 0.026 & 0.770 & 0.233 & 0.086 \\
\hline \multicolumn{7}{|c|}{ Total number of caregivers } \\
\hline $\mathrm{CC}$ & $0.222^{*}$ & $-0.405^{* *}$ & $-0.366 * *$ & 0.183 & 0.122 & $0.228 *$ \\
\hline Significance & 0.034 & 0.000 & 0.000 & 0.082 & 0.250 & 0.029 \\
\hline
\end{tabular}

Notes: *Statistically significant; **highly significant.

Abbreviations: BDI, Beck's Depression Inventory; BPRS, Brief Psychiatry Rating Scale; SF36, Short Form 36; WHO-QOL, World Health Organization quality of life scale; ZCBI, Zerit's Caregiver Burden Inventory.

Table 4 Correlation between patients' symptoms and caregiver burden, where scales measure quality of life and depression

\begin{tabular}{|c|c|c|c|c|c|c|c|}
\hline \multirow[t]{2}{*}{ H\&Y score } & \multirow[t]{2}{*}{$\mathbf{N}$} & \multicolumn{6}{|l|}{ Mean rank } \\
\hline & & WHO-QOL total & SF36 physical health & SF36 mental health & SF36 total & ZCBI & BDI \\
\hline \multicolumn{8}{|c|}{ Kruskal-Wallis test } \\
\hline I & 3 & 80.17 & 80.83 & 71.83 & 78.00 & 7.50 & 10.33 \\
\hline 2 & 30 & 60.28 & 52.83 & 51.70 & 55.33 & 30.70 & 34.27 \\
\hline 3 & 36 & 44.60 & 43.89 & 41.72 & $4 I .6 I$ & 51.31 & 49.89 \\
\hline \multirow[t]{3}{*}{4} & 19 & 26.29 & 37.71 & 46.21 & 38.47 & 59.89 & 57.42 \\
\hline & 3 & 10.67 & 20.67 & 13.17 & 21.00 & 85.83 & 80.00 \\
\hline & $P$-value & 0.000 & 0.017 & 0.043 & 0.010 & 0.000 & 0.000 \\
\hline \multicolumn{8}{|c|}{ Mann-Whitney U-test (P-values) } \\
\hline \multicolumn{8}{|c|}{ Patient variables } \\
\hline YOPD/PD & & 0.199 & 0.482 & 0.343 & 0.528 & 0.947 & 0.410 \\
\hline Hallucinations & & 0.019 & 0.311 & 0.545 & 0.303 & 0.108 & 0.025 \\
\hline Dystonia & & 0.011 & 0.808 & 0.986 & 0.394 & 0.040 & 0.004 \\
\hline Sleep disturbance & & 0.000 & 0.000 & 0.006 & 0.000 & 0.000 & 0.000 \\
\hline Dyskinesia & & 0.000 & 0.005 & 0.051 & 0.002 & 0.000 & 0.000 \\
\hline Thought disorder & & 0.139 & 0.610 & 0.847 & 0.794 & 0.995 & 0.111 \\
\hline Frequent falls & & 0.112 & 0.979 & 0.796 & 0.708 & 0.570 & 0.587 \\
\hline Dementia & & 0.118 & 0.528 & 0.944 & 0.501 & 0.384 & 0.528 \\
\hline
\end{tabular}

Abbreviations: BDI, Beck's Depression Inventory; H\&Y, Hoehn and Yahr staging; PD, Parkinson's disease; SF36, Short Form 36; WHO-QOL, World Health Organization Quality Of Life scale; YOPD, young onset Parkinson's disease; ZCBI, Zerit's Caregiver Burden Inventory. 
Table 5 Linear regression analysis (dependent variable: ZCBI)

\begin{tabular}{|c|c|c|c|c|c|}
\hline & \multirow{2}{*}{$\begin{array}{l}\text { Standardized coefficients } \\
\text { Beta }\end{array}$} & \multirow[t]{2}{*}{$\mathbf{T}$} & \multirow[t]{2}{*}{ P-value } & \multicolumn{2}{|c|}{$95 \%$ confidence interval } \\
\hline & & & & Lower bound & Upper bound \\
\hline Sleep disturbance of patients & 0.206 & 2.284 & 0.025 & 0.817 & II.823 \\
\hline Total number of caregivers & -0.311 & -4.022 & 0.000 & -10.155 & -3.436 \\
\hline UPDRS 3 & 0.255 & 2.999 & 0.004 & 0.108 & 0.532 \\
\hline BDI (patient) & 0.352 & 4.114 & 0.000 & 0.275 & 0.790 \\
\hline
\end{tabular}

Abbreviations: BDI, Beck's Depression Inventory; T, t statistics (coefficient Beta divided by its standard error); UPDRS, Unified Parkinson's Disease Rating Scale; ZCBI, Zerit's Caregiver Burden Inventory.

disturbance (eg, delayed sleep onset, fragmentation of sleep, and REM sleep behavior disorder) all of which adversely affected CB. Sleep problems in patients can increase CB by interfering with their sleep. Presence of dyskinesia and dystonia also increased CB significantly.

Caap-Ahlgren and Dehlin ${ }^{22}$ mentioned patients' functional status, caregivers' depressive symptoms, and social support as determinants of CB. Social support is almost nonexistent in India and hence the onus of caregiving falls solely on the immediate family members, especially spouses. This burden is usually shared by other family members in the joint family system prevalent in India, where younger family members including children and grandchildren live in the same household. Patients' psychiatric symptoms and cognitive impairment were mentioned by Aarsland D et al, ${ }^{14}$ Meara J et al, ${ }^{15}$ Miller E et al, ${ }^{16}$ and Thommessen B et al ${ }^{17}$ in different studies which adversely affected CB. Sleep-related disturbances affecting caregiving commitment was emphasized by Flappe et al. ${ }^{21}$ Martínez-Martín et al $^{19}$ focused on quality of life of caregivers in PD. According to these authors, the patient's functional status and health-related quality of life (HRQoL) was significantly related to the caregiver's strain and quality of life. In another study, Martínez-Martín et al concluded that the presence of caregivers' depression had a significantly negative effect on both CB and HRQoL. The main predictors of CB were caregivers' psychological well-being, patients' mood, and clinical features of PD (especially disability and severity), and HRQoL of patients and caregivers. Recently, in a multicenter cross-sectional study, Martínez-Martín et $a^{20}$ concluded that the caregiver's affective status is the most important factor influencing their burden and health; however, patient-related variables influenced $\mathrm{CB}$ and mood but not the health status.

\section{Disclosure}

The authors report no conflicts of interest in this work.

\section{References}

1. Zarit SH, Todd PA, Zarit JM. Subjective burden of husbands and wives as caregivers: a longitudinal study. Gerontologist. 1986;26:260-266.
2. Hughes AJ, Daniel SE, Kilford L, Lees AJ. Accuracy of clinical diagnosis of idiopathic Parkinson's disease: a clinico-pathological study of 100 cases. J Neurol Neurosurg Psychiatry. 1992;55:181-184.

3. Martínez-Martín P, Forjaz MJ, Frades-Payo B, et al. Caregiver burden in Parkinson's disease. Mov Disord. 2007;22:924-931.

4. Movement Disorder Society Task Force on Rating Scales for Parkinson's Disease. The Unified Parkinson's Disease Rating Scale (UPDRS): status and recommendations. Mov Disord. 2003;18: 738-750.

5. Fahn S, Elton RL, Members of the UPDRS Development Committee. Unified Parkinson's Disease Rating Scale. In: Fahn S, Mardsen CD, Goldstein M, Calne DB, editors. Recent developments in Parkinson's Disease. New York: Macmillan; 1987:153-163.

6. Hoehn MM. The natural history of Parkinson's disease in the prelevodopa and post-levodopa eras. Neurol Clin. 1992;10(2):331-339.

7. Hoehn MM, Yahr MD. Parkinsonism: onset, progression, and mortality. Neurology. 1967;17:427-442.

8. Beck AT, Steer RA. Internal consistencies of the original and revised Beck Depression Inventory. J Clin Psychol. 1984;40:1365-1367.

9. Marsh L, Williams JR, Rocco M, Grill S, Munro C, Dawson TM. Psychiatric comorbidities in patients with Parkinson disease and psychosis. Neurology. 2004;63(2):293-300.

10. Visser M, Marinus J, Stiggelbout AM, Van Hilten JJ. Assessment of autonomic dysfunction in Parkinson's disease: the SCOPA-AUT. Mov Disord. 2004;19:1306-1312.

11. Zarit SH, Reever KE, Bach-Peterson J. Relatives of the impaired elderly: correlates of feelings of burden. Gerontologist. 1980;20(6):649-655.

12. World Health Organization. WHOQoL Study Protocol. WHO 1993 (MNH7PSF/93.9). Available at http://www.who.int/substance_abuse/ research_tools/en/english_whoqol.pdf.

13. Ware JE, Snow KK, Kosinski M, Gandek B. SF-36 $6^{\circledR}$ Health Survey Manual and Interpretation Guide. Boston, MA: New England Medical Center, The Health Institute; 1993.

14. Aarsland D, Larsen JP, Karlsen K, Lim NG, Tandberg E. Mental symptoms in parkinson's disease are important contributors to caregiver distress. Int J Geriat Psychiatry. 1999;14:866-874.

15. Meara J, Mitchelmore E, Hobson P. Use of GDS-15 geriatric depression scale as a screening instrument for depressive symptomatology in patients with Parkinson disease and their carers in the community. Age Ageing. 1999;28:35-38.

16. Miller E, Berrios GE, Politynska BE. Caring for someone with Parkinson's disease: factors that contribute to distress. Int J Geriatr Psychiatry. 1996;11:263-268.

17. Thommessen B, Aarsland D, Braekhus A, Oksengaard AR, Engedal K, Laake K. The psychosocial burden on spouses of the elderly with stroke, dementia and Parkinson's disease. Int J Geriatr Psychiatry. 2002;17:78-84.

18. Carter JH, Stewart BJ, Archbold PG, et al. Living with a person who has Parkinson's disease: the spouses' perspective by stage of disease. Mov Disord. 1998;13:20-28.

19. Martínez-Martín P, Benito-Leoń J, Alonso F, et al. Quality of life of caregivers in Parkinson's disease. Qual Life Res. 2005;14:463-472.

20. Martínez-Martín P, Arroyo S, Rojo-Abuin JM. Burden, Perceived Health Status, and Mood Among Caregivers of Parkinson's Disease Patients. Mov Disord. 2008;23:1673-1680. 
21. Flappe S, Berger K; FAQT Study Investigators. The association between caregiver burden and sleep disturbances in partners of patients with Parkinson's disease. Age Ageing. 2002;31:349-354.
22. Caap-Ahlgren M, Dehlin O. Factors of importance to the caregiver burden experienced by family caregivers of Parkinson's disease patients. Aging Clin Exp Res. 2002;14(5):371-377.

Journal of Parkinsonism \& Restless Legs Syndrome

\section{Publish your work in this journal}

Journal of Parkinsonism and Restless Legs Syndrome is an online, open access, peer-reviewed journal. The journal publishes review articles, historical reviews, original research articles, case reports, letters to the editor, clinical teaching cases, neuroradiology highlights, neuropathology highlights, neuropsychiatry highlights, autobiographies, conference

\section{Dovepress}

proceedings, abstracts and book reviews. The manuscript management system is completely online and includes a very quick and fair peerreview system, which is all easy to use. Visit http://www.dovepress.com/ testimonials.php to read real quotes from published authors.

Submit your manuscript here: http://www.dovepress.com/journal-of-parkinsonism--restless-legs-syndrome-journal 